\title{
Kinetics of steel slag leaching: batch tests and modeling
}

Laurent De Windt ${ }^{1}$, Perrine Chaurand ${ }^{2}$, Jerome Rose ${ }^{2}$

${ }^{1}$ Ecole des Mines de Paris (Mines-ParisTech), Geosciences Dept., France

${ }^{2}$ CEREGE, UMR 6635 CNRS Aix-Marseille Université, 13545 Aix-En-Provence, France

*Corresponding author. Ecole des Mines de Paris, Centre de Géosciences, 35 Rue St-Honoré, 77305 Fontainebleau cedex (France). Email: laurent.dewindt@mines-paristech.fr, tel: +33.1 .64 .69 .49 .42 , fax: +33.1 .64 .69 .47 .13 . 


\begin{abstract}
.
Reusing steel slag as an aggregate for road construction requires to characterize the leaching kinetics and metal releases. In this study, basic oxygen furnace (BOF) steel slag were subjected to batch leaching tests at liquid to solid ratios (L/S) of 10 and 100 over 30 days; the leachate chemistry being regularly sampled in time. A geochemical model of the steel slag is developed and validated from experimental data, particularly the evolution with leaching of mineralogical composition of the slag and trace element speciation. Kinetics is necessary for modeling the primary phase leaching, whereas a simple thermodynamic equilibrium approach can be used for secondary phase precipitation. The proposed model simulates the kineticallycontrolled dissolution (hydrolysis) of primary phases, the precipitation of secondary phases (C-S-H, hydroxide and spinel), the $\mathrm{pH}$ and redox conditions, and the progressive release of major elements as well as the metals $\mathrm{Cr}$ and $\mathrm{V}$. Modeling indicates that the dilution effect of the L/S ratio is often coupled to solubility-controlled processes, which are sensitive to both the $\mathrm{pH}$ and the redox potential. A sensitivity analysis of kinetic uncertainties on the modeling of element releases is performed.
\end{abstract}

Keywords: chromium, geochemical modeling, industrial waste, metallurgical slag, speciation, vanadium. 


\section{Introduction}

Basic oxygen furnace (BOF) steel slag is a residue from the basic oxygen converter in steel-making operations (production of $100 \mathrm{~kg}$ per ton of steel) with an estimated 12 millions tons (Mt) and $8 \mathrm{Mt}$ generated annually in Europe and United States, respectively (Proctor et al., 2000; Motz and Geiseler, 2001). To limit its dumping rate, this residue is partially reused as an aggregate for civil engineering because of its good technical properties (Geiseler, 1996). In recent years, concerns regarding the environment impacts generated by recycled wastes are growing. One of the most important issues is to develop predictive tools to determine the environmental behavior of residues over long periods of time and predict the release of contaminants. Geochemical modeling helps to better identify the leaching processes of waste materials. Furthermore, a model capable of describing contaminant leaching can also assist in improving the development of management options. Indeed, a geochemical model and the associated database can be readily integrated to a reactive transport model, thus transposed to more complex configurations and scenarios to deal with (De Windt et al, 2007b). Developing and calibrating a geochemical model require experimental observations that aim to determine the mechanisms controlling elements mobility within the solid matrix.

Several models have been developed to describe the leaching behavior of various industrial wastes: solidified/stabilized wastes (Halim et al., 2005; De Windt and Badreddine, 2007), municipal solid waste incinerator bottom and fly ash (Meima and Comans, 1997; Van Herck et al., 2000; Astrup et al., 2006), residues from lead metallurgy (Ettler et al., 2005) and chromite ore processing (Geelhoed et al., 2002), or electric arc furnace steel slag (Fällman, 2000; Apul et al., 2005; Suer et al., 2009). To the authors' knowledge, only Huijgen and Comans (2006) have published modeling results related to the leaching of BOF steel slag. Their study focused on mechanisms of aqueous steel slag carbonation for $\mathrm{CO}_{2}$ sequestration 
(Huijgen et al., 2005). They performed a geochemical modeling of the $\mathrm{pH}$-dependent leaching behavior of major and trace elements, based on thermodynamic equilibrium (solubilitycontrol) approach and short-term (48h) batch leaching tests with high L/S ratio.

In the particular case of BOF slag consists of high-temperature de-hydrated solid phases that strongly depart from thermodynamic equilibrium while introduced in the environment. It is therefore crucial to design experiments for which the experimental characterization of the release kinetic is taken into account. Prior to long-term percolation experiment modeling, the first objective of the current modeling study is to interpret batch release of both major elements and trace metals over time, in terms of chemical and mineralogical mechanisms, in a complementary approach to Huijgen and Comans (2006). Indeed batch experiments enable to accurately determine the release of elements over time without modifications due to diffusion and transfer in porous media as for percolation experiments. To that purpose, a model is developed that simulates the initial state of the BOF steel slag, the kinetics of primary phase hydrolysis, the formation of secondary solid phases, the $\mathrm{pH}$ and Eh conditions and the release of major elements and metals. The mixed thermodynamic-kinetic model is validated from experimental results: batch leaching tests (time release curves) and observations of the solid matrix down to a molecular scale. The reuse of BOF steel slag is considered here with a particular attention paid to chromium and vanadium release. These metals are potentially mobile and toxic to the environment (depending of their speciation) and are present in BOF steel slag in relatively high proportions compared to $\mathrm{Cr}$ and $\mathrm{V}$ contents in soils and natural road constructions materials (Proctor et al., 2000; Tossavainen et al., 1999). Crystal-chemistry analyses focused on the evolution with leaching (i) of the solid matrix and its mineralogy and (ii) of the speciation (oxidation state, nature of the bearing-phase) of the trace metals because this essentially affects their mobility. All the crystal-chemistry results mentioned here and 
used to calibrate the model are detailed and discussed in other papers (Chaurand et al., 2006; Chaurand et al., 2007; Chaurand et al., 2007b; Chaurand et al., submitted).

\section{Materials and batch leaching test}

\subsection{Materials}

\subsubsection{Chemical and mineralogical composition}

An industrial lot of Linz Donawitz steel slag (around $200 \mathrm{~kg}$ ) was homogenized and sampled with universal splitters. The leached grains $(0-1 \mathrm{~mm}$ size fraction) were selected by sieving without prior crushing. The $0-1 \mathrm{~mm}$ size fraction is consistent with the standardized batch leaching test procedures (i.e. AFNOR XP X30-469). Its chemical composition (major and trace elements) was determined by ICP-OES analysis (Jobin Ultima-C spectrometer) after mineralization $\left(\mathrm{LiBO}_{2}\right.$ fusion followed by $\mathrm{HNO}_{3}$ digestion). The major element composition of the BOF steel slag is: $\mathrm{CaO}\left(40\right.$ wt.\%), $\mathrm{Fe}_{2} \mathrm{O}_{3}$ (29 wt.\%), $\mathrm{SiO}_{2}$ (13 wt.\%), $\mathrm{MnO}$ (6 wt.\%), $\mathrm{MgO}$ (5 wt.\%), $\mathrm{Al}_{2} \mathrm{O}_{3}\left(2.5\right.$ wt.\%) and $\mathrm{P}_{2} \mathrm{O}_{5}$ (1 wt.\%). BOF steel slag is an alkaline waste with a basicity, its $(\mathrm{CaO}+\mathrm{MgO}) / \mathrm{SiO}_{2}$ ratio being equal to 3.4. Trace elements, chromium $(\mathrm{Cr})$ and vanadium (V), are also detected at a content of $1916 \pm 50 \mathrm{mg} / \mathrm{kg}$ and $679 \pm 25 \mathrm{mg} / \mathrm{kg}$, respectively.

The mineralogical composition of the steel slag was determined in a previous study (Chaurand et al., 2007) using powder X-ray diffraction (XRD, with a Philips PW 3710 X-ray diffractometer using CoK $\alpha$ radiation at $40 \mathrm{kV}$ and $40 \mathrm{~mA}$ ). BOF steel slag consists of a wellcrystallized and heterogeneous matrix composed of primary phases. For the sake of clarity, a distinction is made throughout the paper between the primary phases, which are initially present in the slag, and the secondary phases that may precipitate consequently to the leaching of the former. The main primary solid phases consist of a dicalcium silicate (larnite, $\mathrm{Ca}_{2} \mathrm{SiO}_{4}$ ) 
with phosphorus as impurity, dicalcium aluminoferrite (brownmillerite, $\mathrm{Ca}_{2} \mathrm{Fe}_{2-\mathrm{x}} \mathrm{Al}_{\mathrm{x}} \mathrm{O}_{5}$ with $\mathrm{x}=0.6)$ and a solid solution $(\mathrm{Fe}, \mathrm{Mn}, \mathrm{Mg}) \mathrm{O}$ structurally close to the wüstite $(\mathrm{FeO})$; see Supporting Information. Residual lime $(\mathrm{CaO})$ is also detected and a part of this lime was subjected to quick atmospheric carbonation during the slag transportation and formed calcite $\left(\mathrm{CaCO}_{3}\right)$. These data are in compliance with the literature (Proctor et al., 2000; Motz and Geiseler, 2001; Presslinger and Klepp, 2002).

\subsubsection{Chromium and vanadium speciation in non-leached BOF steel slag}

As already mentioned BOF steel slag also contains trace amounts of elements potentially mobile and toxic to the environment (Geiseler, 1996; Proctor et al., 2000; Motz and Geiseler, 2001). This specially applied to $\mathrm{Cr}$ and $\mathrm{V}$, which are the most abundant trace metals in the studied slag $(1916 \pm 50 \mathrm{mg} / \mathrm{kg}$ and $679 \pm 25 \mathrm{mg} / \mathrm{kg}$, respectively). $\mathrm{Cr}$ is present in non-leached BOF steel slag as $\mathrm{Cr}(\mathrm{III})$ (Chaurand et al., 2006). Two $\mathrm{Cr}(\mathrm{III})$-bearing phases have been identified from laboratory micro-X-ray fluorescence $(\mu-X R F)$ and X-ray absorption spectroscopy at the Cr K-edge (XAS): the brownmillerite and the partly oxidized wustite-type phases (Chaurand et al., 2006; Chaurand et al., submitted; see also Supporting Information for Cr substitution in wüstite).

The microanalytical evaluation of BOF steel slag performed by Presslinger and Klepp (2002) with the aid of a microprobe have shown that $\mathrm{V}$ is essentially contained in the dicalcium aluminoferrite (plus a minor fraction in the dicalcium silicate). XANES (X-ray absorption near edge structure) and micro-XANES measurements performed at the V K-edge have shown that $\mathrm{V}$ is present under two oxidation states: V(III) with an octahedral coordination and V(V) with a tetrahedral coordination (Chaurand et al., 2007b). 


\subsubsection{Size and surface distribution}

Kinetics modeling requires the determination of the surface distribution of solid phases. The present model takes into account the size distribution of the BOF steel slag grains and the surface distribution of every solid phase, since fines react more rapidly than larger grains.

BOF steel slag grains have a density of $3300 \mathrm{~kg} / \mathrm{m}^{3}$ (Motz and Geiseler, 2001; Shen et al., 2009). Because this material presents a very low porosity (Chavepeyr et al., 1979), its specific surface can be estimated from the external surface of the grains assuming a spherical shape. The grains were divided into 3 single size classes, as shown in Table 1: class \#I $(<1 \mu \mathrm{m}, 1$ wt\%), class \#II (1-500 $\mu \mathrm{m}, 69$ wt.\%) and class \#III (500-1000 $\mu \mathrm{m}, 30$ wt.\%), with estimated

specific surfaces around $1.8,0.0040$ and $0.0020 \mathrm{~m}^{2} / \mathrm{g}$, respectively. The wt.\% of each size class was measured after sieving of the selected BOF steel slag grains $(0-1 \mathrm{~mm}$ size fraction). Table 1 presents the surface distribution of primary solid phases, evaluated from 16 images of SEM-BSE (scanning electron microscope-backscatter electron). Image analysis and solid surface calculations performed with the Matlab software were in agreement with the results of Presslinger and Klepp (2002). The wt \% of each primary phase with respect to whole fraction 0-1 mm (Table 1) was evaluated from XRD analysis, secondary and trace element distributions as well as total chemical compositions.

\subsection{Batch leaching test}

Batch leaching tests are the preferred choice at the laboratory scale for regulatory assessment due to their simplicity, reproducibility and short time requirements. The BOF steel slag $(0-1 \mathrm{~mm})$ was submitted to a standardized static leaching protocol, adapted from the European norm NF EN 12457-2. Ultra-pure water $(18.2 \mathrm{M} \Omega / \mathrm{cm})$ was used as leachant. The 
tests were performed under closed conditions, preventing any significant atmospheric inputs of carbon dioxide and oxygen. Single step batch tests were carried out at liquid to solid ratios (L/S) of 10 and 100 for 15 and 30 days, respectively, with end-over rotation (10 rpm) at room temperature. The $\mathrm{pH}$ values measured in the vessels corresponded to the natural $\mathrm{pH}$ resulting from the interactions between BOF steel slag and the leachant. A small volume (a few ml) of the leachate (leachate) was sampled at different times. The sampled volume was replaced by the same volume of ultra-pure water in order to maintain a constant L/S ratio and to limit the perturbation of the system.

Leachates were filtered thought $0.22 \mu \mathrm{m}$ membranes filters, acidified with concentrated $\mathrm{HNO}_{3}$ and subsequently analyzed for $\mathrm{Al}, \mathrm{Ca}, \mathrm{Cr}, \mathrm{Fe}, \mathrm{Mg}, \mathrm{Mn}, \mathrm{Si}$ and $\mathrm{V}$ by plasma emission spectroscopy (ICP-OES, NF EN ISO 11885). The redox state of Cr, Fe and V in the leachate was not determined experimentally, thus the concentrations reported in the figures correspond to total concentrations. The $\mathrm{pH}$ and of the leachates were measured regularly; the later by means of a Pt/calomel reference electrode (corrections were made to the standard hydrogen electrode for comparison with modeling results).

\section{Modeling approach and data}

\subsection{Thermodynamic data}

The geochemical module CHESS of the HYTEC code (van der Lee et al., 2003), version 3.7, was used for modeling the steel slag leaching. The thermodynamic formation constants of the aqueous species and solid phases (minerals) were taken from the EQ3/6 thermodynamic database (Wolery, 1992; version 8.6) because this database contains many high-temperature minerals present in metallurgical slag. The thermodynamic data for the solid phases considered in this study are reported in Table 2. The formation constant of the wüstite-type 
phase in its initial state was calculated by assuming an ideal solid solution between ferrous iron oxide $(\mathrm{FeO})$, manganosite $(\mathrm{MnO})$ and periclase $(\mathrm{MgO})$. The end member fractions were estimated from mass balance based on total chemical composition and element distribution within the main primary phases (further details are given in the Supporting Information). The formation constant was used to estimate its (under-)saturation state with respect to leachate. Wüstite dissolution was then fully controlled by kinetics in the modeling, assuming a congruent process (see Section 3.2).

From crystal-chemistry results and mass balance (see section 2.1.2), the total contents of $\mathrm{Cr}$ and $\mathrm{V}$ in the BOF steel slag have been distributed and integrated to the crystalline formulae of brownmillerite and wüstite-type phases as $\mathrm{Cr}(\mathrm{III})$ and the intermediate redox state V(IV) (see Table 2 and Supporting Information for $\mathrm{Cr}$ substitution in wüstite). The global content in trace metals is $0.35 \%$ (molar fraction) in the case of the brownmillerite-type phase and $0.75 \%$ in the case of the wüstite-type phase. Such low contents did not require recalculating the formation constants of the solid phases. A few additional data for secondary phases were taken from the literature, i.e. three calcium silicate hydrates of increasing $\mathrm{Ca} / \mathrm{Si}$ ratios (C-S-H, Kulik and Kersten, 2001), chromium and iron hydroxides $\left(\mathrm{Cr}(\mathrm{OH})_{3}, \mathrm{Fe}(\mathrm{OH})_{3}\right.$, Appelo and Postma, 1996). The species activities in solution were calculated with the truncated Davies's formula.

\subsection{Thermodynamic equilibrium vs. kinetics}

The chemical reactions in aqueous solution (acid/base, complexation and redox) and the dissolution/precipitation of minerals can be calculated by CHESS either at thermodynamic equilibrium or under kinetic control. A kinetic approach would be the most relevant for modeling mineralogical transformations at $25^{\circ} \mathrm{C}$. However, a kinetic modeling requires to significantly increase the number of modeling parameters (e.g. nucleus surface, kinetic 
constant, $\mathrm{pH}$ catalysis or inhibition effect for every phase), of which many are characterized by strong uncertainties (or even not known). On the contrary, a thermodynamic equilibrium approach needs less data and the data are more accurately known. Though it is not a guarantee that the model will in all cases provide the best descriptions of the data, the later approach simplifies the modeling and facilitates its application to reactive transport model.

Table 3 gives the saturation indices (SI) of the primary solid phases calculated with CHESS with respect to leachate after 15 days (L/S 10) and 30 days (L/S 100) of leaching. Due to uncertainties, the leachate is assumed to be in thermodynamic equilibrium with respect to a given solid phase (mineral) if SI ranges between -0.5 and $0.5 \log$ unit. A positive SI (supersaturated state) indicates that the given solid phase (mineral) may precipitate as a secondary phase. A negative SI (undersaturated state) indicates that the given solid phase (mineral) is not stable with respect to the leachate and may dissolve, provided the solid phase is effectively present in the material. The SI values of the primary solid phases are still strongly negative after 30 days. These solids, which have been formed at high temperature under dehydrated conditions, are in thermodynamic disequilibrium in contact to a low temperature aqueous solution. Modeling their dissolution (hydrolysis) requires, therefore, a kinetic approach. Calcite that is in equilibrium with leachate makes exception. This mineral, which is already a secondary phase formed by lime carbonation during transportation, is wellknown to quickly reach equilibrium.

The case of the other secondary minerals is more complex. Table 3 presents the SI values for potential secondary minerals that were selected from the present mineralogical observations and the literature on alkaline waste leaching (Huijgen and Comans, 2006). Chalcedony, Ca-vanadate, diaspore, hydrogarnet and portlandite cannot precipitate under the leachate chemical conditions according to thermodynamics. Brucite, ferric hydroxide are close to thermodynamic equilibrium. Chromite, $\mathrm{Cr}(\mathrm{III})$ hydroxide and magnetite are 
potentially close to equilibrium, but their saturation states are very sensitive to the redox potential (Sec. 4.1.1). C-S-H phases are either at equilibrium or slightly supersaturated, indicative of relatively fast kinetics of precipitation with respect to the leaching duration. The formation of goethite at the expense of ferric-oxyhydroxide is thermodynamically possible (SI 3) but kinetically constrained. Ferric (oxy)hydroxides, represented here by $\operatorname{Fe}(\mathrm{OH})_{3}$, have been experimentally identified by Huijgen and Comans (2006), even if the exact nature of the minerals remained unknown.

$\mathrm{Cr}, \mathrm{Fe}$ and $\mathrm{V}$ are redox-sensitive elements and their redox reactions that involve the transfer of several electrons are potentially under kinetic control. Nevertheless, thermodynamic equilibrium was assumed to be a reasonable approximation due to the low concentrations measured in the leachates (within the range 10-100 $\mu \mathrm{g} / \mathrm{L}$ ). This approach is also supported by a significant enhancement of $\mathrm{Cr}$ oxidation rate at alkaline $\mathrm{pH}$ (Pillay et al., 2003).

To summarize, priority was given to a certain simplicity of the model, i.e. minimizing the number of input parameters. All aqueous reactions and secondary mineral precipitation were modeled at thermodynamic equilibrium and kinetics was introduced for the dissolution of the oxide primary phases only. Calcite dissolution and precipitation were modeled at thermodynamic equilibrium.

\subsection{Kinetic rate law and data}

The kinetic rate laws for weathering of rock-forming minerals can be in principle applied to the leaching of BOF steel slag since this material consists of well-crystallized minerals. The question of the surface area of primary solid phases has been addressed in Sec. 2.1.3. This section deals with the determination of the kinetic rate constants $k$. A simple kinetic 
formulation without any $\mathrm{pH}$ dependency was used for the dissolution of a primary solid phase $M_{i}$ :

$$
\frac{d\left[M_{i}\right]}{d t}=k_{i} A_{i}\left(\frac{Q_{i}}{K_{i}^{-1}}-1\right)
$$

where the brackets stand for the concentration of the mineral, $k_{i}$ is the intrinsic rate constant far from equilibrium, and $A_{i}$ is the mineral surface area usually derived from the specific surface of the mineral. The term $\left(\frac{Q_{i}}{K_{i}^{-1}}-1\right)$ is the saturation state where $Q_{i}$ stands for the ion activity product and $K_{i}$ is the thermodynamic formation constant. At equilibrium, this term becomes zero likewise the kinetic rate.

To the authors' knowledge rate constants for the present primary solid phases are poorly known in the literature, especially at alkaline $\mathrm{pH}$. Therefore, the rate constants of the geochemical model were derived in three stages: 1) a first estimation from a literature review, 2) an adjustment on the batch tests, 3) a sensitivity analysis (Section 4.3). Mineralogical observations were also used to qualitatively compare the dissolved fractions of each primary phase.

\section{Larnite and lime}

Experimental observations (XRD results coupled with $\mu$-XRF observations) revealed a preferential dissolution of lime and larnite in the altered layer of the leached slag grains (Chaurand et al., 2006; Chaurand et al., submitted). Such observations have also been reported by Huijgen and Comans (2006): portlandite and Ca-silicate were relatively easily leachable over $48 \mathrm{~h}$ batch tests. Rate constants for Ca-orthosilicate (generic formula $\mathrm{Ca}_{2} \mathrm{SiO}_{4}$ ) dissolution are reported in the reviews of mineral kinetics by Brantley (2008) and Schott et al. (2009), but for the acidic $\mathrm{pH}$ domain only. Extrapolation to $\mathrm{pH} 10$ gives the range $5 \times 10^{-9}-$ $10^{-7} \mathrm{~mol} / \mathrm{m}^{2} / \mathrm{s}$ at $25^{\circ} \mathrm{C}$. Rate constants was published for wollastonite $\left(\mathrm{CaSiO}_{3}\right)$ a single-chain 
inosilicate for alkaline $\mathrm{pH}$ (Golubev et al., 2006; Schott et al., 2009). The data are in the range $2.5 \times 10^{-10}-10^{-9} \mathrm{~mol} / \mathrm{m}^{2} / \mathrm{s}$ at $25^{\circ} \mathrm{C}(\mathrm{pH} 10-12)$. The rate constant of larnite used in the model was adjusted to $\mathrm{pH}$ and $\mathrm{Ca}$ release. It is about $10^{-8} \mathrm{~mol} / \mathrm{m}^{2} / \mathrm{s}$ (Table 2), in fair agreement with the above estimates.

Kinetic rate constants of simple oxides are given in Casey et al. (1993) as well as in Brantley (2008), at $25^{\circ} \mathrm{C}$ and the acidic $\mathrm{pH}$ domain. The rate constants continuously decrease with $\mathrm{pH}$ (from $\mathrm{pH} 1$ to 8 ). By extrapolating the $\mathrm{pH}$ dependency to $\mathrm{pH} 10$, the constants of $\mathrm{CaO}$ and $\mathrm{FeO}$ are about $10^{-6}$ and $10^{-9} \mathrm{~mol} / \mathrm{m}^{2} / \mathrm{s}$, respectively. The rate constants of $\mathrm{MgO}$ and MnO lie within these two limits. The rate constant of lime used in the present model was also adjusted to $\mathrm{pH}$ and $\mathrm{Ca}$ release, leading to values in the range $10^{-8}-10^{-7} \mathrm{~mol} / \mathrm{m}^{2} / \mathrm{s}$ (Table 2), i.e. about one or two orders of magnitude smaller than the data of Casey et al. (1993). The steel slag lime was not a pure $\mathrm{CaO}$ phase but also contained a few percents of $\mathrm{FeO}$, which might have stabilized the lime-type phase and slowed down its dissolution.

\section{Brownmillerite- and wüstite-type phases}

The XRD results mentioned above indicated that Fe-bearing phases were still present at high contents in the altered layer, especially the wüstite-type phase. Such observations have also been reported by Huijgen and Comans (2006), with Ca-Fe-oxides virtually insoluble over $48 \mathrm{~h}$ batch tests. The rate constant of the brownmillerite-type phase was roughly adjusted to $\mathrm{Al}$ release leading to a value of $10^{-9} \mathrm{~mol} / \mathrm{m}^{2} / \mathrm{s}$ approximately (Table 2). The same constant was assigned to the wüstite-type phase. This value is within the range of literature data for $\mathrm{FeO}$ hydrolysis (see above), which makes sense for wüstite. The rate constants of $\mathrm{Al}$ and $\mathrm{Fe}(\mathrm{III})$ oxides are several orders of magnitudes smaller compared to FeO (Brantley, 2008; Casey et al., 1993), which may correspond to a smaller rate constant for the brownmilerite-type phase. 
On the other hand, the $\mathrm{CaO}$ fraction is predominant (Table 2); which may destabilize the solid solution and increase the dissolution rate.

\section{$\underline{\text { Calcite }}$}

The dissolution rate constant of calcite is greater than $10^{-6} \mathrm{~mol} / \mathrm{m}^{2} / \mathrm{s}$ under alkaline $\mathrm{pH}$ and $25^{\circ} \mathrm{C}$ (Brantley, 2008).

\subsection{Batch test modeling}

The steel slag mineralogy considered in the modeling is given in Table 1 . The weight contents of each solid phase were estimated from XRD analyses and chemical composition (Sec. 2.1.1). The required quantities of BOF steel slag are added to 1 liter of ultra-pure water for simulating the two L/S ratios. Both chemical evolution (leaching profile) and mineralogical evolution are calculated according to time, the driving force being the kinetics of primary phase dissolution (hydrolysis).

\section{Results and Discussion}

\subsection{BOF steel slag leaching}

\subsubsection{Evolution of $\mathrm{pH}$ and redox potential}

The $\mathrm{pH}$ is a major parameter controlling the leaching of many elements and the model adjustment allows to reproduce its evolution with time in the batch leachates whatever the $\mathrm{L} / \mathrm{S}$ ratio (Fig. 1a). The fast and strong increase in $\mathrm{pH}$ is due to the dissolution of lime and larnite in the finest size fraction (Fig. 2a), class \#I, that yields hydroxyl ions:

$$
\begin{aligned}
& \mathrm{CaO}+\mathrm{H}_{2} \mathrm{O} \rightarrow \mathrm{Ca}^{2+}+2 \mathrm{OH}^{-} \\
& \mathrm{Ca}_{2} \mathrm{SiO}_{4}+2 \mathrm{H}_{2} \mathrm{O} \rightarrow 2 \mathrm{Ca}^{2+}+\mathrm{H}_{2} \mathrm{SiO}_{4}{ }^{2-}+2 \mathrm{OH}^{-}
\end{aligned}
$$


(the three size fractions have been simultaneously used in the modeling, but only the finest and most reactive fraction \#I is shown in Fig. 2). The corresponding $\mathrm{pH}$ value is lower at $\mathrm{L} / \mathrm{S}$ 100 than $\mathrm{L} / \mathrm{S} 10$ due to a dilution effect, leading to natural $\mathrm{pH}$ values of 11.2 and 11.9 respectively. Half of the brownmillerite content of the finest size fraction is dissolved over 30 days, one fourth of the wüstite-type phase (Fig. 2a). Calcite shows a short transient dissolution stage at lower $\mathrm{pH}$ for $\mathrm{L} / \mathrm{S} 100$ but is essentially stabilized at high $\mathrm{pH}$. The dissolution of $2 \%$ of the larnite content of the coarser size fractions (classes \#II-III) accounts for the additional increase of alkalinity and $\mathrm{pH}$ between 10 and 30 days.

The redox potentials $(\mathrm{Eh})$ measured in the leachates were in the range $-0.3-0.3 \mathrm{~V}$. Under the present alkaline $\mathrm{pH}$ conditions, these Eh values imply a mildly reducing environment. The $\mathrm{Fe}(\mathrm{III}) / \mathrm{Fe}(\mathrm{II})$ redox couple is an efficient buffer of redox potential. In the present case, $\mathrm{Fe}(\mathrm{III})$ is brought by the dissolution of brownmillerite and $\mathrm{Fe}(\mathrm{II})$ by the dissolution of the wüstite phase, but the redox potential is likely to be controlled by secondary phases. Fig. 3 shows the sensitivity of the SI of Fe-bearing minerals with respect to Eh, calculated with the data measured at the end of the leaching tests. Ferric-oxyhydroxide and magnetite are close to equilibrium in the Eh range $-0.1-0.2 \mathrm{~V}$. The SI-profiles of these minerals as well as of chromite and $\mathrm{Cr}(\mathrm{OH})_{3}$ intercept the zero axis (equilibrium state) at approximately $0.0-0.05$ V. Though different redox sensitive elements ( $\mathrm{Cr}$ and $\mathrm{Fe})$ are not necessarily in perfect equilibrium at room temperature, this calculated Eh is consistent with the measured Eh values and the secondary phase mineralogy. Formation of the spinel phases chromite and magnetite has been observed in the altered layer of the grains (Chaurand et al., submitted). Micro-Xray Absorption Spectroscopy enabled to reveal the presence of a tiny layer $(<10 \mu \mathrm{m})$ of magnetite and oxy-hydroxide at the surface of the BOF particles. But the quantity of secondary Fe mineral did not seem to be important. It could be due to relative low wüstite dissolution rate as indicated by the model. Chromium hydroxide, either amorphous or crystalline, is 
frequently quoted in the literature as a solubility-controlling mineral (e.g. Deutsch, 1997). Occurrence of ferric-oxyhydroxides in leached BOF steel slag is reported by Huijgen and Comans (2006). In the present calculations, the initial redox potential is defined by assuming that the BOF steel slag already includes a tiny magnetite content.

\subsubsection{Calcium and silicone release}

Calcium and silicone are the most released elements in the batch tests. Ca concentrations in the leachate (Fig. 1b) are about 150 and $75 \mathrm{mg} / \mathrm{L}$ at L/S 10 (after 15 days) and 100 (after 30 days), respectively. Si concentrations are about 5 and $15 \mathrm{mg} / \mathrm{L}$ for the same L/S ratios (Fig. 1c). These values correspond to a total released fraction of $0.5 \%$ and $2.1 \%$ for $\mathrm{Ca}$ at $\mathrm{L} / \mathrm{S} 10$ and 100 , respectively, and of $0.1 \%$ and $2.9 \%$ for $\mathrm{Si}$ (after 15 days leaching). There is no straightforward relationship between the concentration and the dilution factor (i.e. no proportionality), demonstrating a solubility control by secondary phases. The calculated concentration profiles are in good agreement with the experimental data. In particular, $\mathrm{Ca}$ concentration decreases with $\mathrm{L} / \mathrm{S}$ whereas Si concentration increases.

According to Eqs. 2-3, $\mathrm{Ca}$ and $\mathrm{Si}$ release in solution is due to the partial dissolution of lime and larnite during leaching test (especially the finest size fraction). Precipitation of C-S$\mathrm{H}$ is predicted by the model (Fig. 2b). C-S-H were identified as the hydration products of larnite during leaching (Chaurand et al, submitted). Huijgen and Comans (2006) emphasized the formation of both C-S-H and ettringite $\left(\mathrm{Ca}_{6} \mathrm{Al}_{2}\left(\mathrm{SO}_{4}\right)_{3}(\mathrm{OH})_{12}: 26 \mathrm{H}_{2} \mathrm{O}\right)$ in their leached $\mathrm{BOF}$ steel slag samples. The later phase is unlikely with the present steel slag due to its very low sulfate content. More generally, C-S-H is a common product of the alteration of alkaline wastes such as bottom ash of incinerated municipal waste (Speiser et al., 2000). C-S-H 1.7 that presents a $\mathrm{Ca} / \mathrm{Si}$ atomic ratio of 1.7 is preferentially formed at $\mathrm{L} / \mathrm{S} 10$, while $\mathrm{C}-\mathrm{S}-\mathrm{H} 0.8$ is exclusively formed at L/S 100 . This is an intrinsic property of C-S-H: the more alkaline the 
$\mathrm{pH}$ is, the higher the $\mathrm{Ca} / \mathrm{Si}$ ratio is (Sugiyama and Fujita, 2006). Chalcedony does not precipitate in the model consistently with negative, under-saturated, SI values for both leachates (Table 3).

The bicarbonate/carbonate concentrations of the leachate were not measured. It is very likely that calcite remained in equilibrium with leachate during all the duration of the batch tests. The carbonate content derived from the (measured) Ca concentration and calcite equilibrium is about $0.5 \mathrm{mg} / \mathrm{L}$, i.e. low.

\subsubsection{Iron, magnesium and aluminum release}

$\mathrm{Fe}, \mathrm{Mg}$ and $\mathrm{Al}$ are slightly released elements. Their concentrations in the leachate remain low during the leaching tests: they do not exceed $0.02 \mathrm{mg} / \mathrm{L}$ for $\mathrm{Fe}, 0.1 \mathrm{mg} / \mathrm{L}$ for $\mathrm{Mg}$, and 1 $\mathrm{mg} / \mathrm{L}$ for $\mathrm{Al}$. Mn releases, which are not modeled in the current study, were equal or below 10 $\mu \mathrm{g} / \mathrm{L} . \mathrm{Mg}$ and $\mathrm{Al}$ are associated to Fe-bearing phases of BOF steel slag. The low mobility of these three elements has to be related to the leaching behavior of their bearing phases. Fig. 1 shows the model predictions for these elements together with the measured data in a graph of logarithmic concentration versus time.

$\mathrm{Mg}$ release is also very weak; its total release fraction remains $<0.02 \%$. The exclusive $\mathrm{Mg}$ bearing-phase in non-altered BOF steel slag is the wüstite-type phase (a solid solution). Only 0.05 wt.\% of the most reactive size fraction (the finest, fraction \#1) is dissolved (Fig. 2a) after 30 days. This phase is still present at high content in the altered layer. In fact, during leaching this phase tends, chemically and structurally, to pure wüstite (FeO). Mineralogical observations have indicated that $\mathrm{Mg}$ is preferentially released from the solid solution but mainly retained in the altered layer by the formation of a new hydrated Mg-rich phase (Chaurand et al., submitted). Huijgen and Comans (2006) assessed that Mg leaching could be adequately modeled at $\mathrm{pH}>9.5$ provided brucite controlled the magnesium solubility. In the 
present modeling too, $\mathrm{Mg}$ concentration in the leachates is fairly well calculated whilst taking into account solubility-controlling phases. The low $\mathrm{Mg}$ release is first induced by the slow dissolution of the wüstite-type phase and become controlled by brucite precipitation in a second stage when the $\mathrm{pH}$ reaches highly alkaline values (after 2 and 10 days at L/S 10 and 100 , respectively).

After 15 days leaching, $\mathrm{Al}$ total released fraction reaches 0.09 and $0.4 \%$ at $\mathrm{L} / \mathrm{S} 10$ and 100 , respectively. Al release is essentially associated to the dissolution of the brownmilleritetype phase. Half of the brownmillerite content of the finest size fraction is dissolved (Fig. 2a) after 30 days, whereas only 0.25 wt. $\%$ of the fraction \#2 is affected by hydrolysis. Mineralogical observations have revealed a preferential mobility of $\mathrm{Al}$ during the alteration of the brownmillerite-type phase (Chaurand et al., submitted). This phase is subjected to an incongruent dissolution leading to the formation of a dicalcium ferrite, poor in Al but still containing the other impurities such as Cr. This incongruent dissolution could not be implemented in the present model. At L/S 10, the leaching curve of $\mathrm{Al}$ can be adequately modeled by the solubility of diaspore that precipitates in the modeling (Fig. 2c). This secondary phase has also been detected in the altered layer (Chaurand et al., submitted).

The case of iron has already been discussed in Sec. 4.1.1. Fe release is very weak (total released fraction $<0.02 \%$ ) and linked to the dissolution of brownmillerite and wüstite-type phases. As mentioned previously, these phases are subjected to very slow and incongruent dissolution during leaching. And the actual Fe dissolved concentration could be controlled by ferric (oxy)hydroxide and magnetite precipitation (Fig. 2c). Magnetite precipitation is favored at higher $\mathrm{pH}$, thus at $\mathrm{L} / \mathrm{S} 10$. The redox potential is controlled by the couple $\mathrm{Fe}(\mathrm{OH})_{3}-$ magnetite, as discussed in Sec. 4.1.1. The calculated final Eh values are -0.01 and $0.01 \mathrm{~V}$ at L/S 10 and 100, respectively. These values are very close to the redox potentials derived from the SI values calculated with the experimental data, around $0.05 \mathrm{~V}$ (Fig. 3, Sec. 4.1.1). The 
calculated Fe concentrations are one order of magnitude lower than the leachate experimental data. Complementary calculations showed that Fe concentrations were not sensitive to the redox potential in the range $-0.05-0.15 \mathrm{~V}$. The discrepancy might arise from a colloidal $\mathrm{Fe}$ fraction, not filtrated at $0.22 \mu \mathrm{m}$ and considered as dissolved. Further investigations are required to better define the role of colloidal release, if any.

\subsection{Trace metals release}

\subsubsection{Chromium release}

$\mathrm{Cr}$ release is very low (total released fraction $<0.05 \%$ ). Initially $\mathrm{Cr}$ is present in $\mathrm{BOF}$ steel slag as $\mathrm{Cr}(\mathrm{III})$ and associated with brownmillerite and wüstite-type phases. Mineralogical observations and spectroscopic analyses indicated that $\mathrm{Cr}$ solubility is controlled by the formation of a spinel-type phase similar to chromite, $\mathrm{FeCr}_{2} \mathrm{O}_{4}$ in the altered layers of leached slag (Chaurand et al., 2006). Cr retention can be linked to the formation of this secondary phase that tends to incorporate Cr(III) ions in a very stable form. In particular, no oxidation of $\mathrm{Cr}(\mathrm{III})$ to $\mathrm{Cr}(\mathrm{VI})$ occurred in the solid matrix during leaching. Chromite formation is also predicted by modeling for the two L/S ratios (Fig. 2c), as the result of brownmillerite and wüstite dissolution under the redox control of the couple $\mathrm{Fe}(\mathrm{OH})_{3}-$ magnetite.

However, the calculated chromium concentrations in the leachate are largely underestimated while controlled by chromite solubility compared to experimental data (Fig. 4a). Modeling is much better when solubility is controlled by $\mathrm{Cr}(\mathrm{III})$-hydroxide (Fig. 4b), which could be considered as an alternative phase to model the hydrated leached layer. The maximum chromium concentrations are 15 and $2 \mu \mathrm{g} / \mathrm{L}$ at L/S 10 and 100, respectively. Without any solubility control, the maximum $\mathrm{Cr}$ concentrations are 325 and $55 \mu \mathrm{g} / \mathrm{L}$ for the same L/S ratios. Chromium concentration is intimately related to $\mathrm{pH}$ evolution, as indicated 
by the plateau at both $\mathrm{pH}$ and chromium concentration at $\mathrm{L} / \mathrm{S} 10$. With this respect, Cr release profile is very similar to the $\mathrm{Ca}$ and Fe ones (Fig. 1b,e); the solubility of the later could also be controlled by hydroxides. Though controlled by a $\mathrm{Cr}(\mathrm{III})$ phase, the anion $\mathrm{CrO}_{4}{ }^{2-}$ is the predominant aqueous species in the leachates. This is consistent with the present mildly reducing domains represented in the Pourbaix diagram of chromium (Fig. 4c).

\subsubsection{Vanadium release}

Vanadium release is higher than chromium release, its total released fraction reaches 0.06 and $1.7 \%$ at L/S 10 and 100 , respectively after 15 days of leaching. Vanadium release is driven by the incongruent dissolution of its initial bearing-phase (the brownmillerite-type phase). Micro-XANES measurements showed that V oxidation state and symmetry exhibits an important evolution from the unaltered to the altered phases. The oxidation of the initial V(III) to V(V) during leaching can partially explain the V mobility (Chaurand et al., 2007b). Moreover, secondary V-bearing phase was not detected experimentally in the leached layer.

Under alkaline conditions, equilibrium thermodynamic calculations shows that vanadium is always present in solution in the $\mathrm{V}(\mathrm{V})$ redox state whatever the redox potential, $\mathrm{VO}_{3} \mathrm{OH}^{2-}$ being the main aqueous species. The dissolved $\mathrm{V}$ concentrations are too low as to be controlled by Ca-vanadate in the modeling. This is also pointed out by strongly negative SI values of Ca-vanadate with respect to the leachate chemistry (Table 3), as well as in literature (Huijgen and Comans, 2006; Cornelis et al., 2008). Modeling is in good agreement with the experimental data in terms of concentration ranges $(20-100 \mathrm{mg} / \mathrm{L})$, but fails to reproduce the inversion in the two L/S ratios compared to a pure dilution effect. The anionic character of $\mathrm{VO}_{3} \mathrm{OH}^{2-}$ implies that sorption on aluminum and ferric hydroxides is negligible since the sorption of oxyanions required positively charged (protonated) surfaces, which is unlikely at alkaline $\mathrm{pH}$. Oxyanions can be integrated to C-S-H skeletons to some extent (Gougar et al., 
1996; Cornelis et al., 2008), and C-S-H precipitation is larger at the L/S ratio of 10. However, such a vanadium enrichment of C-S-H was not experimentally investigated in the present study.

\subsection{Sensitivity analysis with respect to kinetic rate constants}

The dissolution rate of a primary phase is proportional to the product of the kinetic rate constant $k_{i}$ by the surface $A_{i}$ (Eq. 1$)$. The reactive surfaces were relatively well characterized by contrast to the rate constants. Therefore, for the purpose of sensitivity analysis, the base case constants of Table 2 corresponding to the hydration of brownmillerite, larnite and wüstite type phases have been either multiplied or divided by a factor 10 . This means a range of two orders of magnitude, which corresponds for instance to the range of data found in literature for Ca-orthosilicates.

As discussed in Sections 4.1.1-2, the evolution of $\mathrm{pH}$ and $\mathrm{Ca}$ release with time are essentially linked to the dissolution of lime and larnite. Fig. 5 shows that a factor 10 decrease of the corresponding constants clearly underestimates the experimental data. The data are closely bounded by the curves calculated with the base case and the factor 10 increase (i.e. $10^{-}$ ${ }^{8}-10^{-7} \mathrm{~mol} / \mathrm{m}^{2} / \mathrm{s}$, respectively), the larger discrepancy being found for $\mathrm{Ca}$ at $\mathrm{L} / \mathrm{S}=10$. Globally, the best adjustment is obtained with the base case value of larnite $\left(10^{-8} \mathrm{~mol} / \mathrm{m}^{2} / \mathrm{s}\right)$ and a lime constant within $10^{-8}-10^{-7} \mathrm{~mol} / \mathrm{m}^{2} / \mathrm{s}$. Larnite dissolution also release silicon into the leachate, this element being controlled by $\mathrm{CSH}$ precipitation (Section 4.1.2). In the calculations, the silicone concentration is thus a function of $\mathrm{pH}$ and $\mathrm{Ca}$ concentration via the solubility product of $\mathrm{CSH}$ phases. The calculation based on the greater rate constant underestimates silicon concentration (Fig. 5), especially at $\mathrm{L} / \mathrm{S}=10$ (related to higher $\mathrm{pH}$ and 
Ca concentrations). This demonstrates the sensitivity of the model with respect to the CSH control of silicone concentration.

Aluminum release is an indicator of the kinetics of brownmillerite dissolution. As shown in Fig. 5, Al concentration in the leachate is clearly underestimated with the lower limit of the rate constant $\left(10^{-10} \mathrm{~mol} / \mathrm{m}^{2} / \mathrm{s}\right)$ and overestimated with the higher limit $\left(10^{-8} \mathrm{~mol} / \mathrm{m}^{2} / \mathrm{s}\right)$. It is worth noting the precipitation of hydrogarnet (instead of diaspore) and the related decrease of $\mathrm{Al}$ concentration at the most alkaline $\mathrm{pH}$ values (i.e. higher rate constant and $\mathrm{L} / \mathrm{S}=10$ ). The release of $\mathrm{V}$ is directly proportional to the rate variation in the model since Ca-vanadate never precipitates: i.e. factors 10 and 0.1 against the reference state, respectively. The variation of $\mathrm{Cr}$ concentration with respect to the rate constant sensitivity is slightly smoothened by the solubility-control of chromium hydroxide. For example, the calculated $\mathrm{Cr}$ concentrations at $\mathrm{L} / \mathrm{S}=100$ are $0.3,2$ and $9 \mu \mathrm{g} / \mathrm{L}$ by increasing order of rate constant.

\section{Conclusions}

The geochemical model based on detailed mineralogical and petrophysical data has simulated the main leaching processes (dissolution/hydration of primary phases, precipitation of secondary phases) of the BOF steel slag and the subsequent release of major and trace elements. The model indicates that the dilution effect of the $\mathrm{L} / \mathrm{S}$ ratio is often coupled to solubility-controlled processes, which have been shown to be sensitive to both the $\mathrm{pH}$ and the redox potential. The model has given priority to a thermodynamic equilibrium approach for secondary phases formations because it requires less parameters than kinetics. However, kinetics is necessary for modeling the primary phase alteration of BOF steel slag. That situation is also relevant for the evolution in aqueous environments of many alkaline wastes formed at high temperature. Unfortunately, little or no kinetic data is available in the literature for the solid phases of interest. An estimate of the kinetic rate constants (based on a rather 
good estimation of the reactive surface distributions) was derived from the batch tests and shown to be applicable at both L/S ratios. However, a more accurate study of the primary mineral kinetics may be further performed to determine the $\mathrm{pH}$-dependency (e.g. with $\mathrm{pH}-$ buffered solutions).

Implication of the batch test results for dumping/reuse is not straightforward and is scenario dependent. They might correspond to nearly closed condition systems such as backfilling of excavations (and possibly the core of road subbase layers). The hydrolysis of BOF steel slag induced a fast increase of alkalinity $(\mathrm{Ca}-\mathrm{OH})$ of leachate within a few days. Nevertheless, the kinetics of hydrolysis was relatively moderate (especially at L/S = 100), and essentially driven by the finest size fraction (class \#I in the present case). The contribution of these fractions will decrease during alteration and the smaller reactive surfaces of the other fractions should lead to a lower instantaneous impact. Furthermore, the dissolution kinetics of brownmillerite- and wüstite-types phases are slower than those of lime and larnite. The longterm release of elements and metals may become essentially controlled by the solubility of secondary phases, potentially those pointed out by this study. In superficial open systems such as roadside slopes, carbonation by atmospheric $\mathrm{CO}_{2}$ may buffer the $\mathrm{pH}$ and enhance calcite precipitation, whereas oxidation may change $\mathrm{Cr}$ speciation. The present geochemical model can be integrated to different scenarios and, based on the current work, model validation on 18 months outdoor percolating experiments at the pilot scale (in lysimeter) are under progress.

\section{Acknowledgements}

Two anonymous reviewers are gratefully acknowledged for their constructive and detailed comments. P. Chaurand and J. Rose thank ADEME (the French Agency for Environment and Energy Management) and INERIS (the French Institute of Industrial Environment and Risks) 
for having supported this work, as well as their colleagues from LCPC (Laboratoire Central des Ponts et Chaussées) for having provided the BOF steel slag samples.

\section{References}

Appelo, C.A.J., Postma, D., 1996. Geochemistry, groundwater and pollution, A.A. Balkema Publishers, Leiden, The Netherlands.

Apul, D. S., Gardner, K. H., Eighmy, T. T., Fallman, A.-M., Comans, R. N. J., 2005. Simultaneous application of dissolution/precipitation and surface complexation/surface precipitation modeling to contaminant leaching. Environ. Sc. Techn. 39, 5736-5741.

Astrup, T., Dijkstra, J. J., Comans, R. N. J., van der Sloot, H. A., Christensen, T. H., 2006. Geochemical Modeling of Leaching from MSWI Air-Pollution-Control Residues. Environ. Sci. Technol. 40, 3551-3557.

Brantley, S.L., 2008. Kinetics of mineral dissolution, in "Kinetics of water-rock interactions", Brantley/Kubicki/White Eds, Springer, New-York (USA), pp. 151-210.

Casey, W.H., Banfield, J.F., Westrich, H.R., McLaughlin, L., 1993. What do dissolution experiments tell us about natural weathering?, Chem. Geol. 105, 1-15.

Chaurand, P., Rose, J., Proux, O., Hazemann, J. L., Briois, V., Salome, M., Susini, J., Ferrasse, J. H., Borschneck, D., Bottero, J. Y. 2006. In Environmental impact of steel slag reused as aggregates in road manufacturing: Molecular mechanisms of chromium and vanadium release, 13th International Conference on X-Ray Absorption Fine Structure (XAFS13), Stanford, CA, Jul 09-14,; Hedman, B.; Painetta, P., Eds. Amer Inst Physics: Stanford, CA, 2006; pp 199-201.

Chaurand, P., Rose, J., Briois, V., Olivi, L., Hazemann, J. L., Proux, O., Domas, J., Bottero, J. Y., 2007. Environmental impacts of steel slag reused in road construction: A crystallographic and molecular (XANES) approach. J. Hazard. Mater. 139, 537-452. 
Chaurand, P., Rose, J., Briois, V., Salome, M., Proux, O., Nassif, V., Hazemann, J. L., Olivi, L., Susini, J., Bottero, J. Y., 2007b. New methodological approach for the Vanadium Kedge XANES interpretation: Application to the speciation of Vanadium in oxide phases from steel slag. J. Phys. Chem. B 111, 5101-5110.

Chaurand, P., Rose, J., Proux, O., Salome, M., Borschneck, D., Ferrasse, J. H., Hazemann, J. L., Susini, J., Francois, D., Domas, J., Bottero, J. Y., Evolution of chromium speciation within steel slag during leaching experiment: a bulk and micro X-ray spectroscopic study. Submitted for review.

Chavepeyr, G., Dumortier, C., Gohy, C., Levert, J. M., Riquier, Y., 1979. Etude de la composition minéralogique des scories LD. Silic. Ind. 44, 217-33.

Cornelis, G., Johnson, C.A., Van Gerven, T., Vandecasteele, C. (2008). Leaching mechanisms of oxyanionic metalloid and metal species in alkaline solid wastes: A review. Appl. Geochem. 23, 955-976.

Deutsch, J.S., 1997. Groundwater Geochemistry: Fundamentals and Applications to Contamination, CRC Press, Washington (USA).

De Windt, L. and Badreddine, R. (2007). Modelling of long-term dynamic leaching tests applied to solidified/stabilised waste. Waste Manage. 27, 1638-1647.

De Windt, L., Badreddine, R., Lagneau, V., 2007b. Long-term reactive transport modelling of stabilized/solidified waste: from dynamic leaching tests to disposal scenarios. J. Hazard. Mater. 139, 529-536.

Ettler, V., Mihaljevic, M., Sebek, M., Strnad, L., 2005. Leaching of APC residues from secondary $\mathrm{Pb}$ metallurgy using single extraction tests: the mineralogical and the geochemical approach. J. Hazard. Mater. 121, 149-157.

Fällman, A.-M., 2000. Leaching of chromium and barium from steel slag in laboratory and field tests - a solubility controlled process ?. Waste Manage. 20, 149-154. 
Geelhoed, J. S., Meeussen, J. C. L., Hillier, S., Lumsdon, D. G., Thomas, R. P., Farmer, J. G., Paterson, E., 2002. Identification and geochemical modeling of processes controlling leaching of $\mathrm{Cr}(\mathrm{VI})$ and other major elements from chromite ore processing residue. Geochim. Cosmochim. Ac. 66, 3927-3942.

Geiseler, J., 1996. Use of steelworks slag in Europe. Waste Manage. 16, 59-63.

Golubev, S.V., Pokrovsky, O.S., Schott, J., 2006. Experimental determination of the effect of dissolved $\mathrm{CO}_{2}$ on the dissolution kinetics of $\mathrm{Mg}$ and $\mathrm{Ca}$ silicates at $25^{\circ} \mathrm{C}$. Chem. Geol. $217,227-238$.

Gougar, M.L.D., Scheetz, B.E., Roy, D.M., 1996. Ettringite and C-S-H Portland cement phases for waste ion immobilization: A review. Waste Manage. 16, 295-303.

Halim, C. E., Short, S. A., Scott, J. A., Amal, R., Low, G., 2005. Modelling the leaching of $\mathrm{Pb}, \mathrm{Cd}, \mathrm{As}$, and $\mathrm{Cr}$ from cementitious waste using PHREEQC. J. Hazard. Mater. 125, 4561.

Huijgen, W. J. J., Comans, R. N. J., 2006. Carbonation of steel Slag for $\mathrm{CO}_{2}$ sequestration: leaching of products and reaction mechanisms. Environ. Sci. Technol. 40, 2790-2796.

Huijgen, W. J. J., Witkamp, G., Comans, R. N. J., 2005. Mineral $\mathrm{CO}_{2}$ sequestration by steel slag carbonation. Environ. Sci. Techn. 39, 9676-9682.

Kulik, D. and Kersten, M., 2001. Aqueous solubility diagrams for cementitious waste stabilization systems: II, end-member stoichiometries of ideal calcium silicate hydrate solid solution. J. Am. Ceram. Soc. 84, 3017-3026.

van der Lee, J., De Windt, L., Lagneau, Goblet, P., 2003. Module-oriented modeling of reactive transport with HYTEC. Comput. Geosci. 29, 265-275.

Meima, J. A., Comans, R. N. J., 1997. Geochemical modeling of weathering reactions in municipal solid waste incinerator bottom ash. Environ. Sci. Technol. 31, 1269-1276. 
Motz, H., Geiseler, J., 2001. Products of steel slags an opportunity to save natural resources. Waste Manage. 21, 285-293.

Pillay, K., von Blottnitz, H., Petersen, J. 2003. Ageing of chromium(III)-bearing slag and its relation to the atmospheric oxidation of solid chromium(III)-oxide in the presence of calcium oxide. Chemosphere 52, 1771-1779. Amer. J. Sc. 278, 179-216.

Presslinger, H., Klepp, K. O., 2002. Vanadium in converter slags. Steel Res. 73, 522-525.

Proctor, D. M., Fehling, K. A., Shay, E. C., Wittenborn, J. L., Avent, C., Bigham, R. D., Connolly, M., Lee, B., Shepker, T. O., Zak, M. A., 2000. Physical and Chemical Characteristics of Blast Furnace, Basic Oxygen Furnace, and Electric Arc Furnace Steel Industry Slags. Environ. Sci. Technol. 34, 1576-1582.

Schott, J., Pokrovsky, O.S., Oelkers, E.H., 2009. The link between mineral dissolution/precipitation kinetics and solution chemistry, Rev. Miner. Geochem. 70, 207258.

Shen, D. H., Wu, C. M., Du, J. C., 2009. Laboratory investigation of basic oxygen furnace slag for substitution of aggregate in porous asphalt mixture. Constr. Build. Mater. 23, 453461.

Speiser, C., Baumann, T., Niessner, R., 2000. Morphological and chemical characterization of calcium-hydrate phases formed in alteration processes of deposited municipal solid waste incinerator bottom ash, Environ. Sci. Technol. 34, 5030-5037.

Suer, P., Lindqvist, J.-E., Arm, M., Frogner-Kockum, P., 2009. Reproducing ten years of road ageing - Accelerated carbonation and leaching of EAF steel slag. Sci. Total Environ. 407, $5110-5118$

Sugiyama, D., Fujita, T., 2006. A thermodynamic model of dissolution and precipitation of calcium silicate hydrates. Cement Concr. Res. 36, 227-237. 
Tossavainen, M., Forssberg, E, 1999. The potential leachability from natural road constructions materials. Sci. Total Environ. 239, 31-47.

Van Herck, P., Van der Bruggen, B., Vogels, G., Vandecasteele, C., 2000. Application of computer modelling to predict the leaching behaviour of heavy metals from MSWI fly ash and comparison with a sequential extraction method. Waste Manage. 20, 203-210.

Wolery, T. E., 1992. EQ3/6: A software Package for Geochemical Modelling of Aqueous Systems: Package Overview and Installation Guide; UCRL-MA-110662 PT I ed.; Lawrence Livermore National Laboratory (USA). 


\section{Figure captions.}

Fig. 1. Experimental (exp.) and calculated (calc.) evolution with time of $\mathrm{pH}$ (a) and concentration of the main BOF steel slag elements in the batch leachates (b-f).

Fig. 2. Dissolution of the primary phases of the finest size fraction (class \#I) (a) and the subsequent formation of secondary phases $(b, c)$.

Fig. 3. Sensitivity of the saturation indices of redox-buffering minerals with respect to the redox potential (Eh) of the batch solution.

Fig. 4. Experimental and calculated evolution with time of trace metal $(\mathrm{Cr}, \mathrm{V})$ concentrations in the batch leachates (a, b, d); the pH-Eh diagram (c) has been calculated with the present thermodynamic database (activity $\mathrm{Fe}=$ activity $\mathrm{Cr}=10^{-6}$, the grey zone corresponds to the batch leaching conditions).

Fig. 5. Sensitivity analysis with respect to the kinetic rate constants $k$ of the primary phases (all the constants $k$ of Table 2 are either divided or multiplied by a factor 10). 
(a) $\mathrm{pH}$

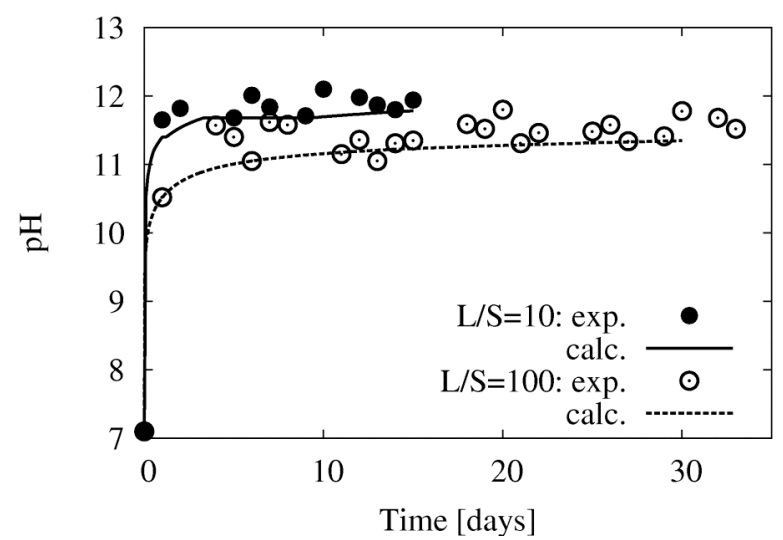

(c) $\mathrm{Si}$

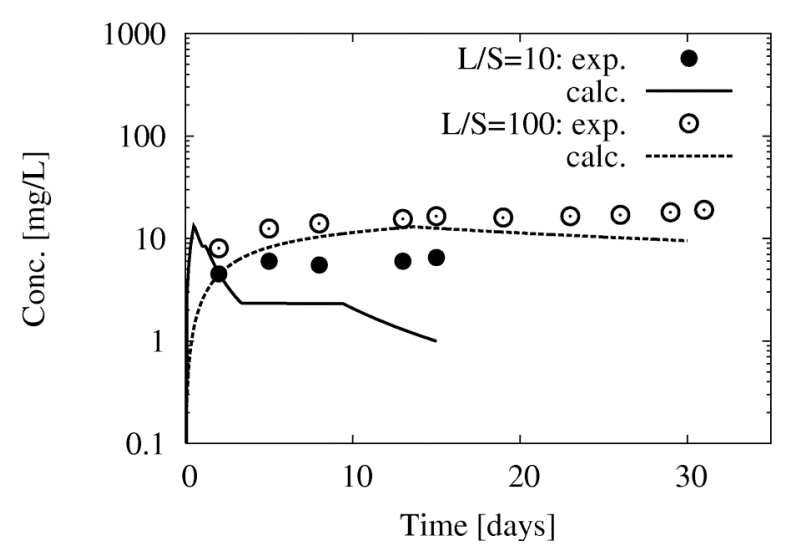

(e) $\mathrm{Fe}$

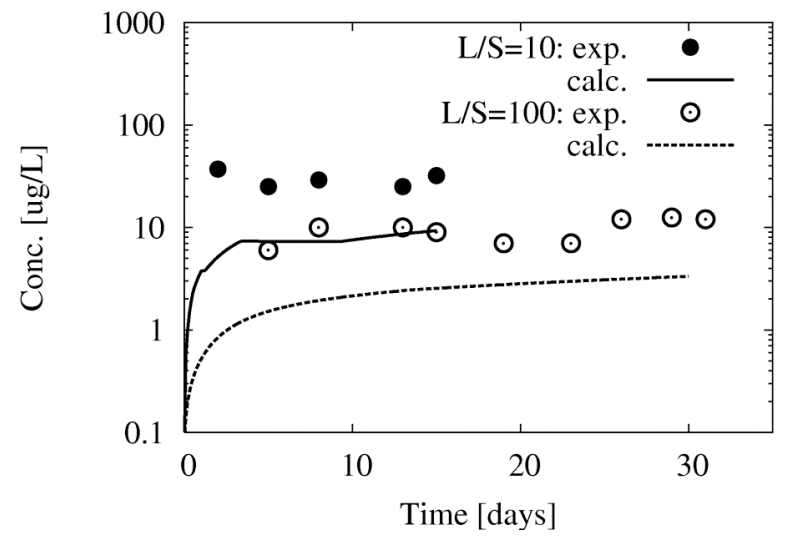

(b) $\mathrm{Ca}$

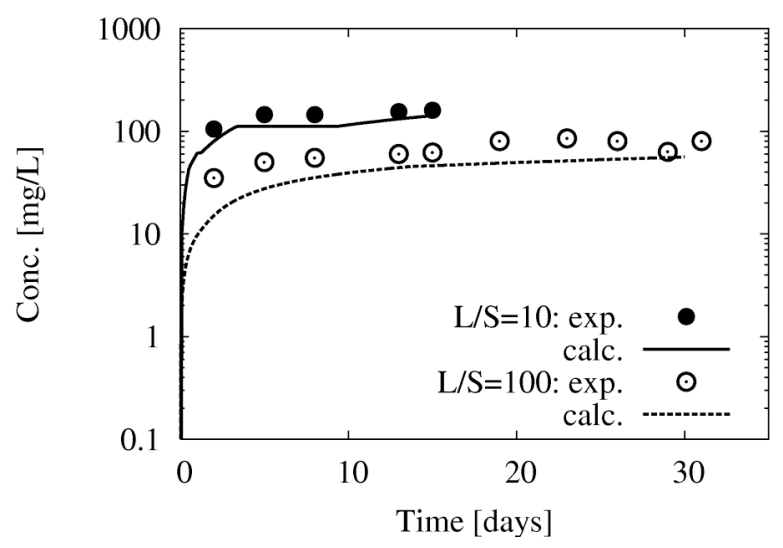

(d) Al

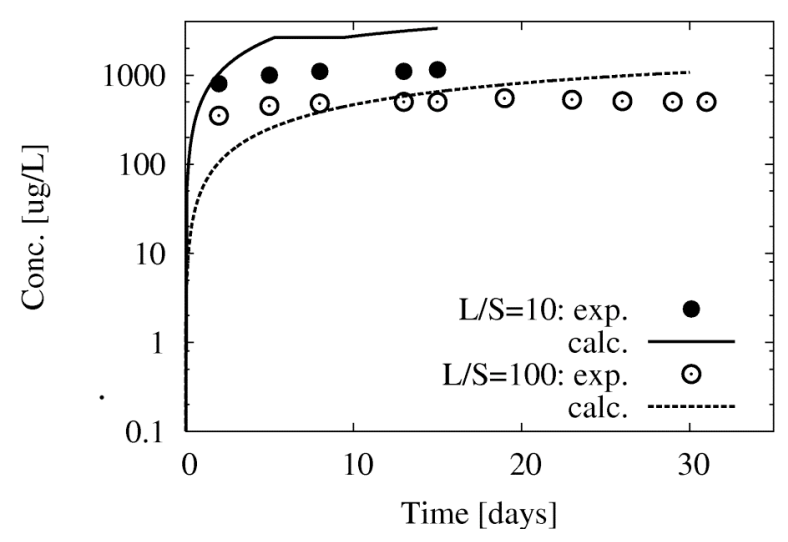

(f) $\mathrm{Mg}$

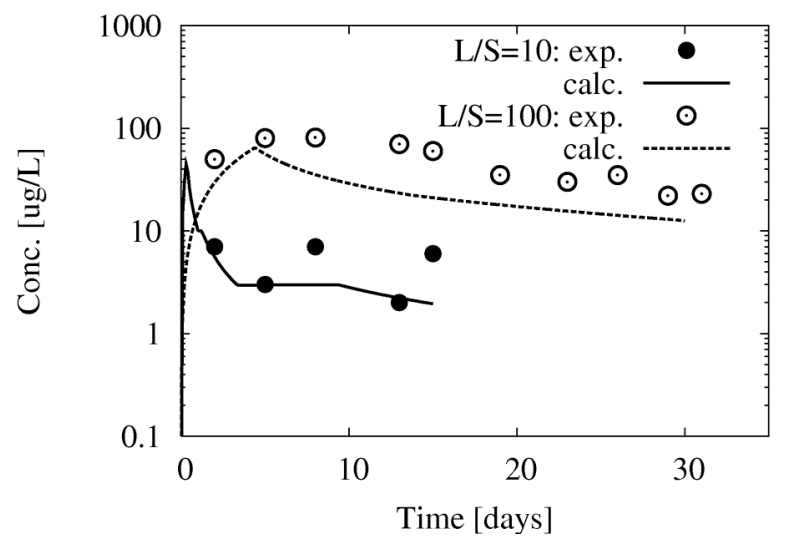

Fig. 1. Experimental (exp.) and calculated (calc.) evolution with time of $\mathrm{pH}$ (a) and concentration of the main BOF steel slag elements in the batch leachates (b-f). 
$\mathbf{L} / \mathbf{S}=\mathbf{1 0}$

(a)

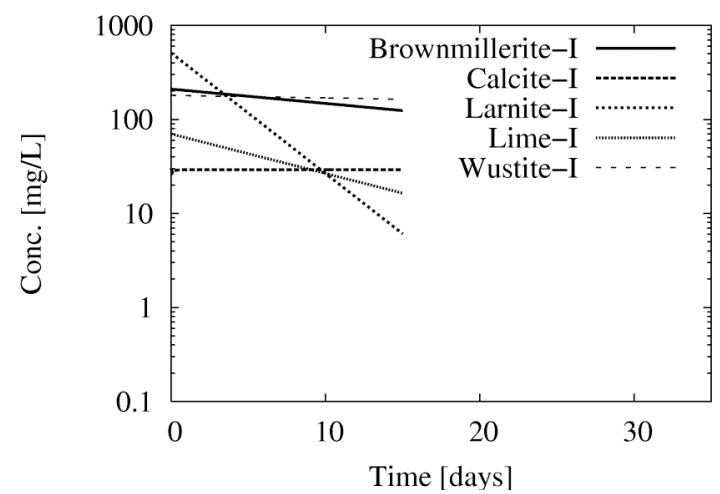

(b)

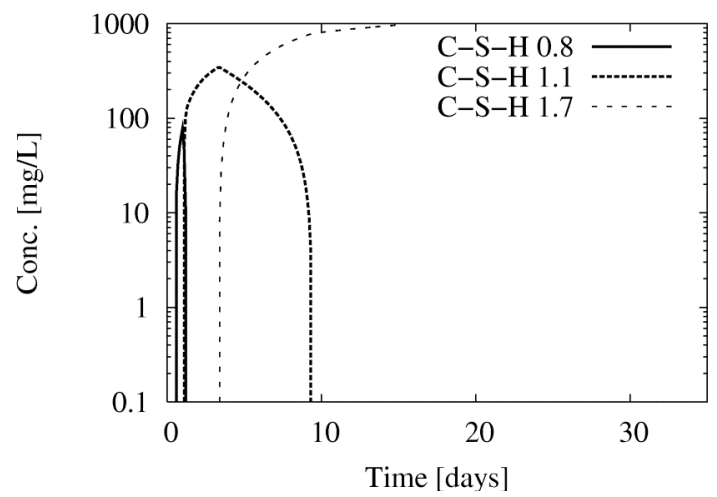

(c)

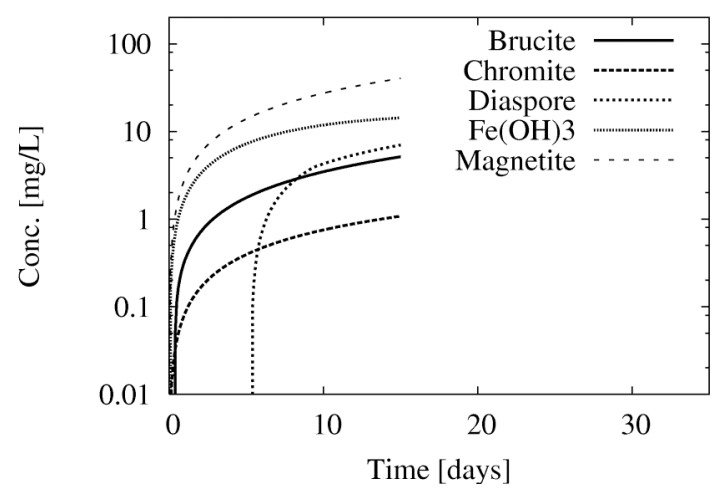

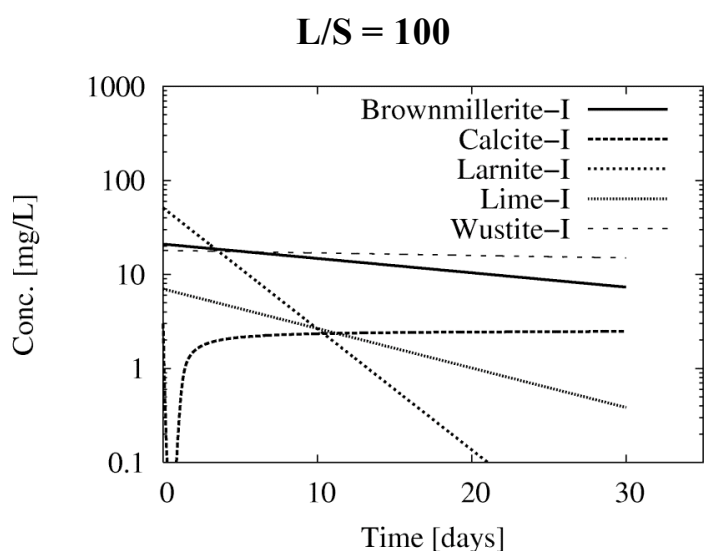
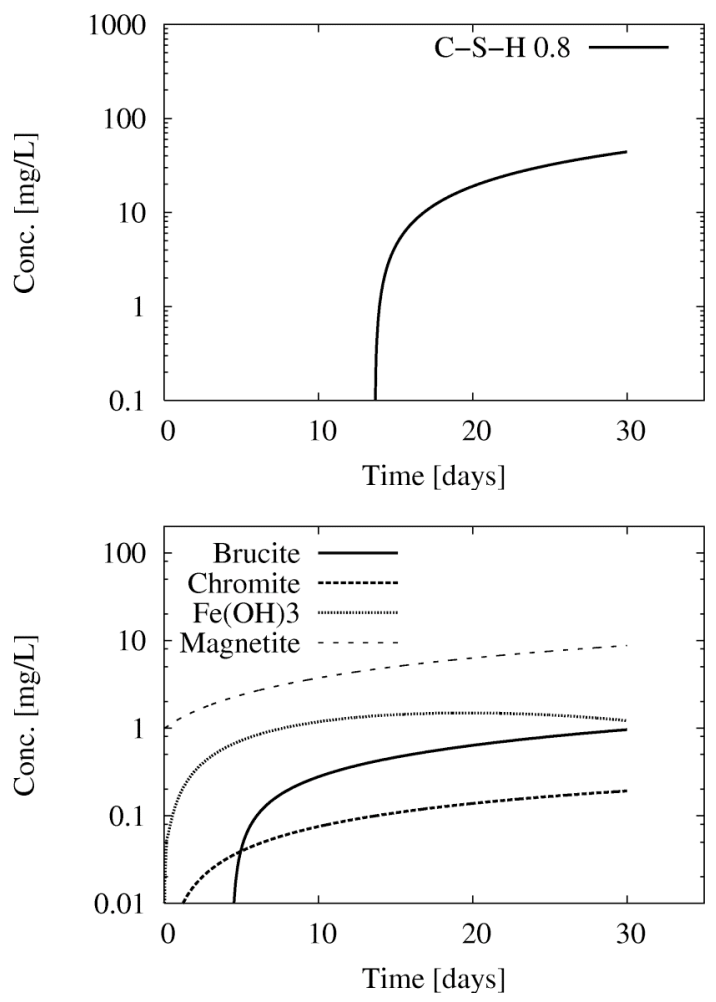

Fig. 2. Dissolution of the primary phases of the finest size fraction (class \#I) (a) and the subsequent formation of secondary phases $(b, c)$. 

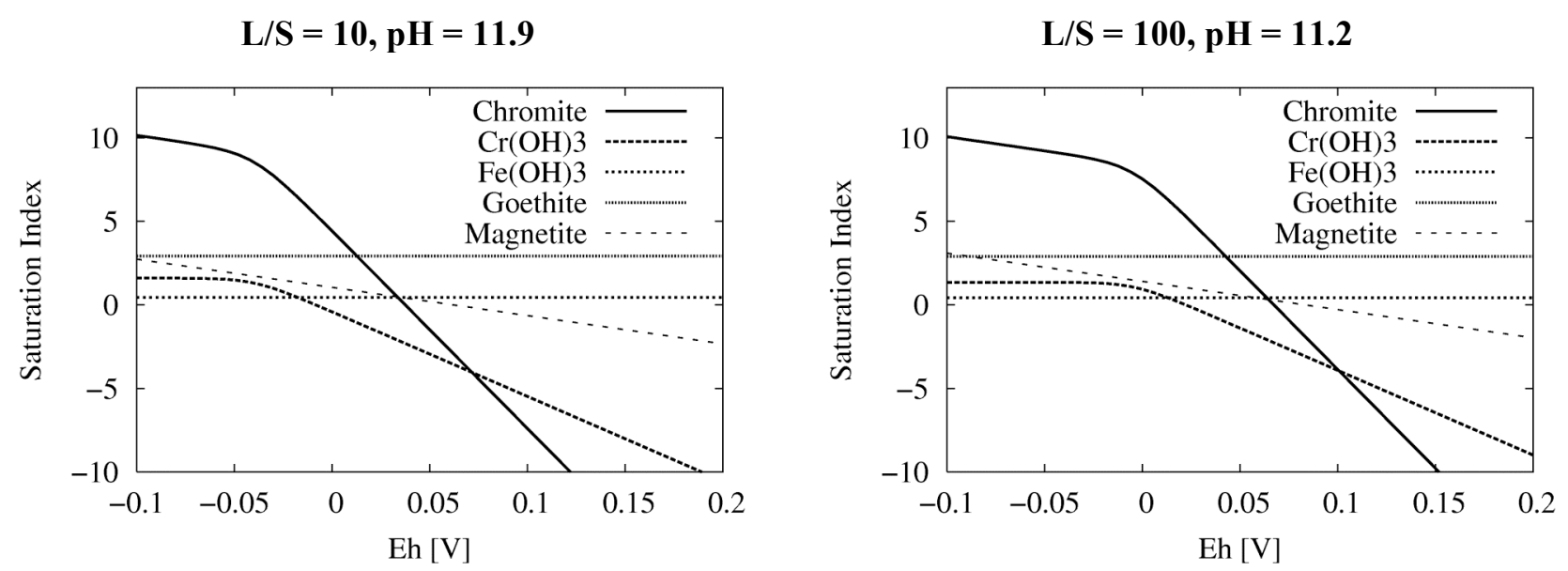

Fig. 3. Sensitivity of the saturation indices of redox-buffering minerals with respect to the redox potential (Eh) of the batch solution. 
(a) Cr: controlled by chromite

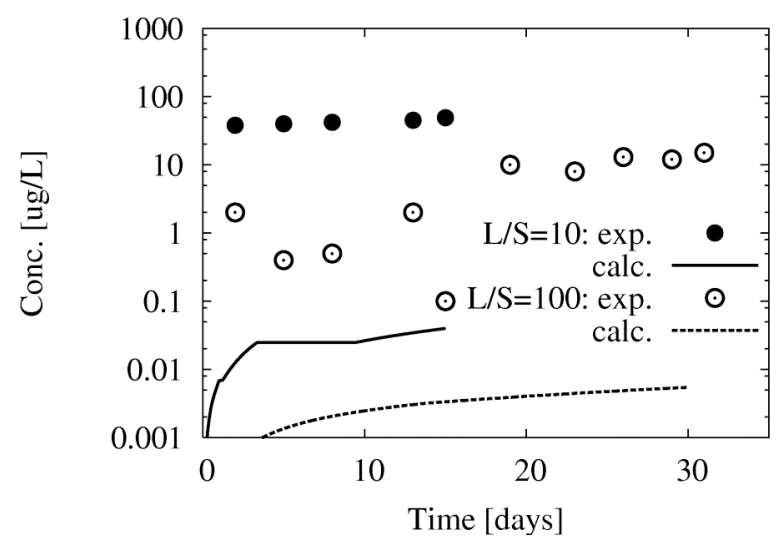

(c) $\mathrm{Cr}: \mathrm{pH}-$ Eh diagram

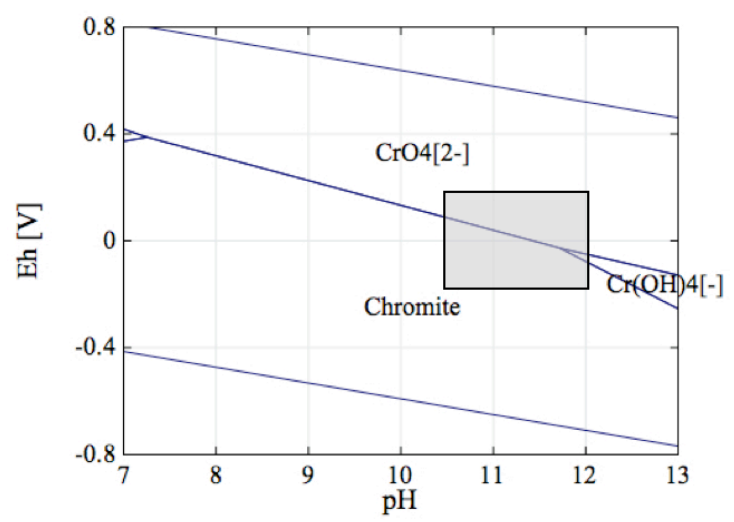

(b) Cr: controlled by $\mathrm{Cr}(\mathrm{OH})_{3}$

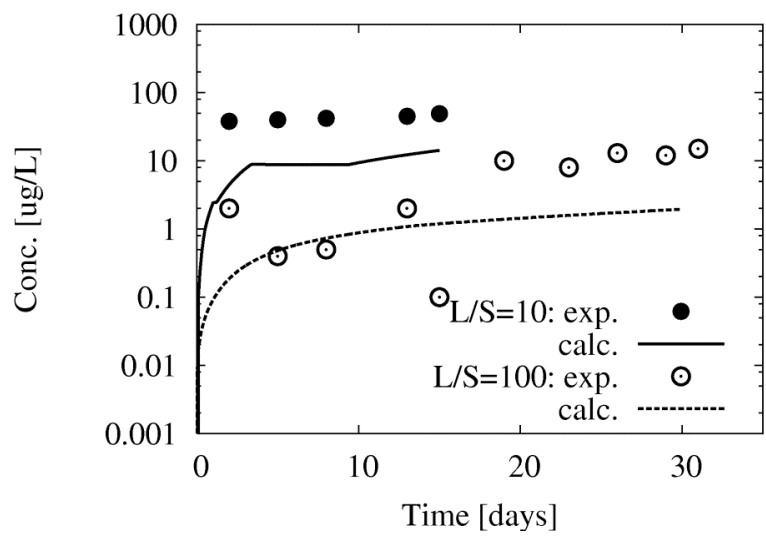

(d) $\mathrm{V}$

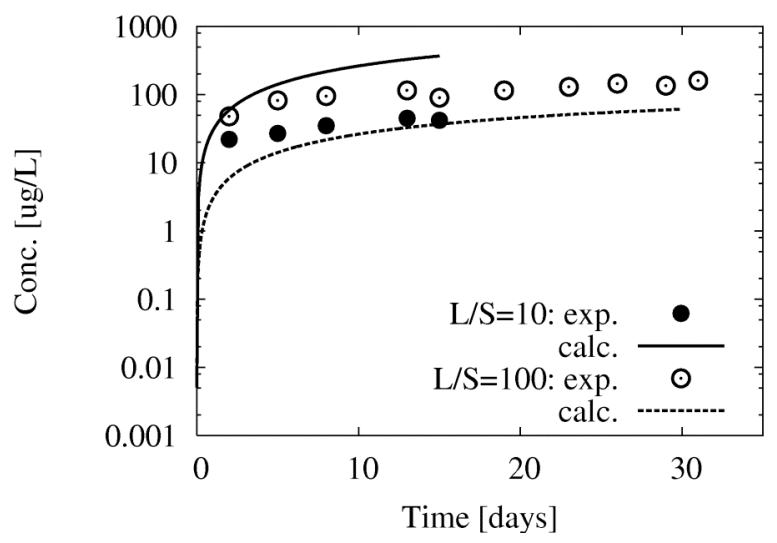

Fig. 4. Experimental and calculated evolution with time of trace metal $(\mathrm{Cr}, \mathrm{V})$ concentrations in the batch leachates $(\mathrm{a}, \mathrm{b}, \mathrm{d})$; the $\mathrm{pH}$-Eh diagram (c) has been calculated with the present thermodynamic database (activity $\mathrm{Fe}=$ activity $\mathrm{Cr}=10^{-6}$, the grey zone corresponds to the batch leaching conditions). 

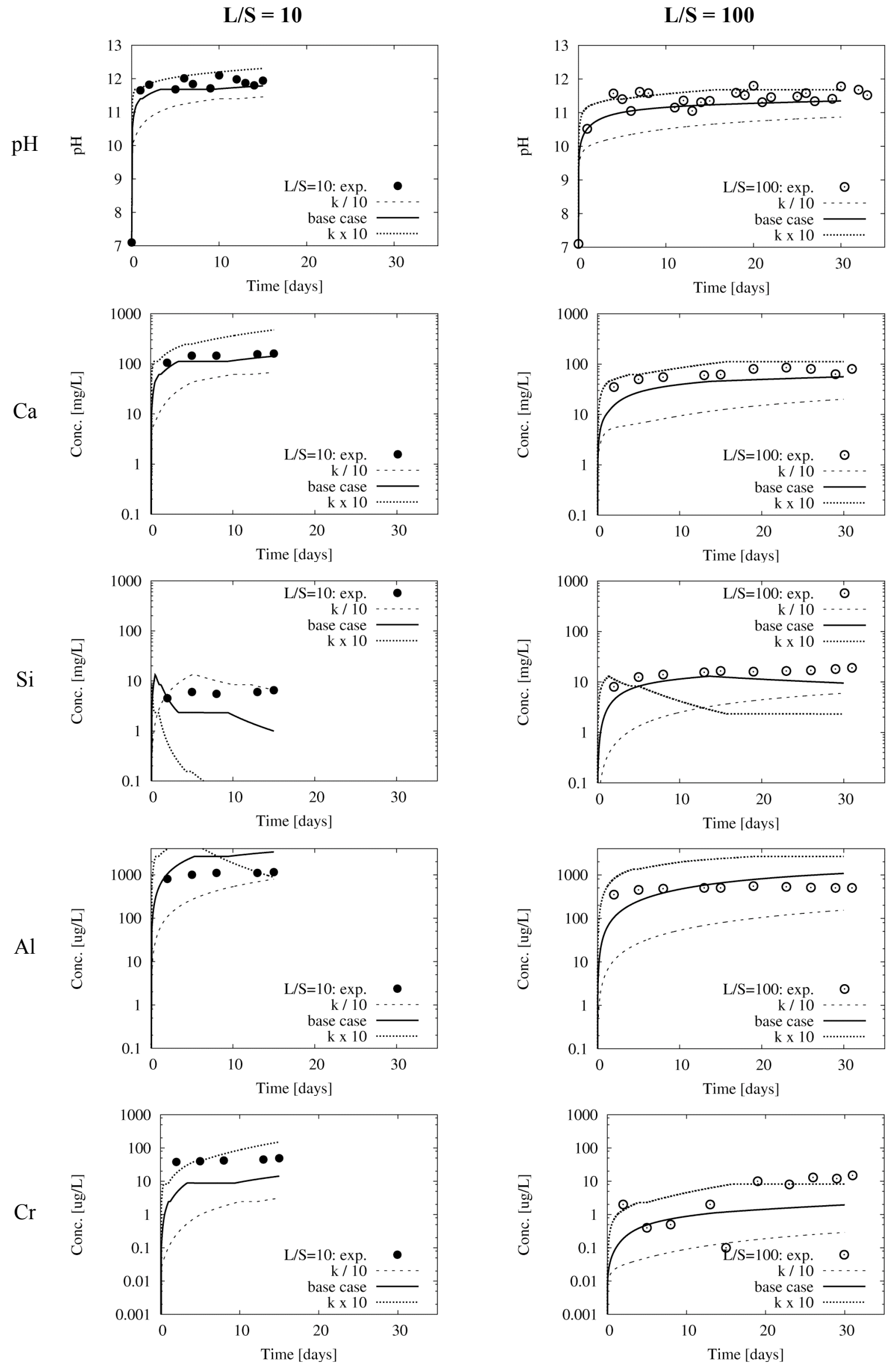

Fig. 5. Sensitivity analysis with respect to the kinetic rate constants $k$ of the primary phases (all the constants $k$ of Table 2 are either divided or multiplied by a factor 10). 
Table 1.

Primary solid phases of the BOF steel slag: weight content, surface distributions and calculated specific surfaces for the 3 size fractions (class \#I, \#II and \#III).

\begin{tabular}{|c|c|c|c|c|c|}
\hline Solid phases & $\begin{array}{r}\text { Brownmillerite } \\
\text {-type phase }\end{array}$ & Calcite & Larnite & Lime & $\begin{array}{r}\text { Wüstite } \\
\text {-type phase }\end{array}$ \\
\hline Content $^{(1)}\left[w t^{\%} \%\right]$ & 21 & 3 & 51 & 7 & 18 \\
\hline Surface distribution $^{(1)}[\%]$ & 19 & 4 & 58 & 8 & 11 \\
\hline \multicolumn{6}{|l|}{ Specific surface $\left[\mathrm{m}^{2} / \mathrm{g}\right]$} \\
\hline $\begin{array}{r}\text { Class \#I }(<1 \mu \mathrm{m}): \\
1 \mathrm{wt}^{(1)}, 1.8 \mathrm{~m}^{2} / \mathrm{g}^{(2)}\end{array}$ & 1.6 & 2.4 & 2.0 & 2.0 & 1.15 \\
\hline $\begin{array}{r}\text { Class \#II }(1-500 \mu \mathrm{m}): \\
30 \mathrm{wt}^{(1)}, 0.0040 \mathrm{~m}^{2} / \mathrm{g}^{(2)}\end{array}$ & 0.0037 & 0.0055 & 0.0045 & 0.0045 & 0.0025 \\
\hline $\begin{array}{l}\text { Class \#III }(500-1000 \mu \mathrm{m}) \text { : } \\
69 \mathrm{wt}^{(1)}, 0.0019 \mathrm{~m}^{2} / \mathrm{g}^{(2)}\end{array}$ & 0.0017 & 0.0026 & 0.0021 & 0.0021 & 0.0012 \\
\hline
\end{tabular}

(1) With respect to whole fractions, i.e. 0-1000 $\mu \mathrm{m}$.. (2) Total specific surface calculated for the 5 primary phases. 
Table 2.

Logarithmic values of the thermodynamic equilibrium constants $(\mathrm{K})$ and kinetic rate constants $(\mathrm{k})$ for the solid phases considered in the models.

\begin{tabular}{|c|c|c|c|}
\hline Solid phases & Reaction & $\begin{array}{r}\log \mathrm{K} \\
\left(25^{\circ} \mathrm{C}\right) \\
\end{array}$ & $\begin{array}{r}\log \mathrm{k} \\
\left(25^{\circ} \mathrm{C}\right) \\
\end{array}$ \\
\hline \multicolumn{4}{|l|}{ Primary phases } \\
\hline $\begin{array}{r}\text { Brownmillerite- } \\
\text { type phase }\end{array}$ & $\begin{array}{l}2 \mathrm{Ca}^{2+}+0.6 \mathrm{Al}^{3+}+1.363 \mathrm{Fe}^{3+}+0.013 \mathrm{Cr}^{3+}+0.018 \mathrm{VO}^{2+}+ \\
4.982 \mathrm{H}_{2} \mathrm{O} \rightarrow \mathrm{Ca}_{2} \mathrm{Fe}_{1.363} \mathrm{Al}_{0.6} \mathrm{Cr}_{0.013} \mathrm{~V}_{0.018} \mathrm{O}_{5}+9.964 \mathrm{H}^{+}\end{array}$ & -65.2 & $-9^{(1)}$ \\
\hline Calcite & $\mathrm{Ca}^{2+}+\mathrm{HCO}_{3}^{-} \rightarrow \mathrm{CaCO}_{3}+\mathrm{H}^{+}$ & -1.85 & \\
\hline Larnite & $2 \mathrm{Ca}^{2+}+\mathrm{SiO}_{2}(\mathrm{aq})+2 \mathrm{H}_{2} \mathrm{O} \rightarrow \mathrm{Ca}_{2} \mathrm{SiO}_{4}+4 \mathrm{H}^{+}$ & -38.45 & $-8^{(1)}$ \\
\hline Lime $^{(3)}$ & $\mathrm{Ca}^{2+}+\mathrm{H}_{2} \mathrm{O} \rightarrow \mathrm{CaO}+2 \mathrm{H}^{+}$ & -32.58 & $-8^{(1,3)}$ \\
\hline $\begin{array}{l}\text { Wüstite- } \\
\text { type phase }\end{array}$ & $\begin{array}{l}0.385 \mathrm{Fe}^{2+}+0.3 \mathrm{Mg}^{2+}+0.3 \mathrm{Mn}^{2+}+0.015 \mathrm{Cr}^{3+}+\mathrm{H}_{2} \mathrm{O} \rightarrow \\
\mathrm{Fe}_{0.385} \mathrm{Mn}_{0.3} \mathrm{Mg}_{0.3} \mathrm{Cr}_{0.015} \mathrm{O}+2.015 \mathrm{H}^{+}\end{array}$ & -17.7 & $-9^{(1)}$ \\
\hline \multicolumn{4}{|l|}{ Secondary phases } \\
\hline Brucite & $\mathrm{Mg}^{2+}+2 \mathrm{H}_{2} \mathrm{O} \rightarrow \mathrm{Mg}(\mathrm{OH})_{2}+2 \mathrm{H}^{+}$ & -16.30 & \\
\hline Ca-vanadate & $1.5 \mathrm{Ca}^{2+}+\mathrm{VO}_{2}^{+}+2 \mathrm{H}_{2} \mathrm{O} \rightarrow \mathrm{Ca}_{1.5} \mathrm{VO}_{4}+4 \mathrm{H}^{+}$ & -19.48 & \\
\hline Chalcedony & $\mathrm{SiO}_{2}(\mathrm{aq}) \rightarrow \mathrm{SiO}_{2}$ & 3.72 & \\
\hline Chromite & $\mathrm{Fe}^{2+}+2 \mathrm{Cr}^{3+}+4 \mathrm{H}_{2} \mathrm{O} \rightarrow \mathrm{FeCr}_{2} \mathrm{O}_{4}+8 \mathrm{H}^{+}$ & -15.17 & $-{ }^{(2)}$ \\
\hline Cr(III)-hydroxide & $\mathrm{Cr}^{3+}+3 \mathrm{H}_{2} \mathrm{O} \rightarrow \mathrm{Cr}(\mathrm{OH})_{3}+3 \mathrm{H}^{+}$ & -7.85 & - \\
\hline C-S-H 0.8 & $1.8 \mathrm{Ca}^{2+}+2.3 \mathrm{SiO}_{2}(\mathrm{aq})+5.4 \mathrm{H}_{2} \mathrm{O} \rightarrow \mathrm{Ca}_{1.8} \mathrm{Si}_{2.3} \mathrm{O}_{10} \mathrm{H}_{7.2}+3.6 \mathrm{H}^{+}$ & -24.19 & $-(2)$ \\
\hline C-S-H 1.1 & $1.1 \mathrm{Ca}^{2+}+\mathrm{SiO}_{2}(\mathrm{aq})+3.1 \mathrm{H}_{2} \mathrm{O} \rightarrow \mathrm{Ca}_{1.1} \mathrm{SiO}_{5.1} \mathrm{H}_{4}+2.2 \mathrm{H}^{+}$ & -16.82 & $-^{(2)}$ \\
\hline C-S-H 1.7 & $1.7 \mathrm{Ca}^{2+}+\mathrm{SiO}_{2}(\mathrm{aq})+4.3 \mathrm{H}_{2} \mathrm{O} \rightarrow \mathrm{Ca}_{1.7} \mathrm{SiO}_{6.3} \mathrm{H}_{5.2}+3.4 \mathrm{H}^{+}$ & -29.20 & $-(2)$ \\
\hline Diaspore & $\mathrm{Al}^{3+}+2 \mathrm{H}_{2} \mathrm{O} \rightarrow \alpha-\mathrm{AlOOH}+3 \mathrm{H}^{+}$ & -7.16 & $-(2)$ \\
\hline Fe(III)-hydroxide & $\mathrm{Fe}^{3+}+3 \mathrm{H}_{2} \mathrm{O} \rightarrow \mathrm{Fe}(\mathrm{OH})_{3}+3 \mathrm{H}^{+}$ & -3.0 & $-{ }^{(2)}$ \\
\hline Goethite & $\mathrm{Fe}^{3+}+2 \mathrm{H}_{2} \mathrm{O} \rightarrow \alpha-\mathrm{FeOOH}+3 \mathrm{H}^{+}$ & -0.54 & $-(2,4)$ \\
\hline Hydrogarnet & $2 \mathrm{Al}^{3+}+3 \mathrm{Ca}^{2+}+12 \mathrm{H}_{2} \mathrm{O} \rightarrow \mathrm{Ca}_{3} \mathrm{Al}_{2}(\mathrm{OH})_{12}+12 \mathrm{H}^{+}$ & -78.94 & $-(2)$ \\
\hline Magnetite & $\mathrm{Fe}^{2+}+2 \mathrm{Fe}^{3+}+4 \mathrm{H}_{2} \mathrm{O} \rightarrow \mathrm{Fe}_{3} \mathrm{O}_{4}+8 \mathrm{H}^{+}$ & -10.47 & $-{ }^{(2)}$ \\
\hline Portlandite & $\mathrm{Mg}^{2+}+2 \mathrm{H}_{2} \mathrm{O} \rightarrow \mathrm{Ca}(\mathrm{OH})_{2}+2 \mathrm{H}^{+}$ & -22.56 & $-{ }^{(2)}$ \\
\hline
\end{tabular}

(1) A sensitivity analysis has been performed according to \pm 1 unit log with respect to the kinetic rate constants $k$. (2) The precipitation and dissolution of calcite and all secondary phases are calculated at thermodynamic equilibrium. (3) The steel slag lime was not a pure $\mathrm{CaO}$ phase but also contained a few percents of FeO. (4) Not allowed to precipitate (see Section 3.2). 


\section{Table 3.}

Saturation indices (SI) of primary and secondary solid phases calculated with respect to the batch leachate composition after 15 days $(\mathrm{L} / \mathrm{S}=10)$ and 30 days $(\mathrm{L} / \mathrm{S}=100)$.

\begin{tabular}{rrr}
\hline Solid phases & $\mathrm{L} / \mathrm{S}=10$ & $\mathrm{~L} / \mathrm{S}=100$ \\
\hline Brown.- type phase & -15.8 & -17.8 \\
Calcite & 0.1 & 0.0 \\
Larnite & -1.9 & -3.3 \\
Lime & -11.5 & -12.7 \\
Wüstite-type phase & -6.6 & -6.8 \\
& & \\
Brucite & 0.5 & 0.5 \\
Ca-vanadate & -3.7 & -3.9 \\
Chalcedony & -1.8 & -1.0 \\
Chromite & $-3-3^{(*)}$ & $-3-3{ }^{(*)}$ \\
Cr(III)-hydroxide & $-3-3^{(*)}$ & $-3-3{ }^{(*)}$ \\
Diaspore & -2.5 & -2.1 \\
C-S-H 0.8 & 0.9 & 0.9 \\
C-S-H 1.1 & 0.9 & 0.4 \\
C-S-H 1.7 & 1.0 & -0.1 \\
Fe(III)-hydroxide & 0.4 & 0.4 \\
Goethite & 2.9 & 2.9 \\
Hydrogarnet & -6.5 & -9.2 \\
Magnetite & $-1-1^{(*)}$ & $-1-1^{(*)}$ \\
Portlandite & -1.5 & -2.7 \\
\hline
\end{tabular}

(*) SI values sensitive to the redox potential. 